Atmos. Chem. Phys. Discuss., 4, 6823-6836, 2004

www.atmos-chem-phys.org/acpd/4/6823/

SRef-ID: 1680-7375/acpd/2004-4-6823

(C) European Geosciences Union 2004

\title{
A global satellite view of aerosol cloud interactions
}

C. Luo

Institute for Computational Earth System Science, University of California, Santa Barbara, California 6832 Ellison Hall University of California, Santa Barbara, CA 93106, USA

Received: 9 September 2004 - Accepted: 7 October 2004 - Published: 22 October 2004

Correspondence to: C. Luo (chaoluo@bren.ucsb.edu)
A global satellite view of aerosol cloud interactions

C. Luo

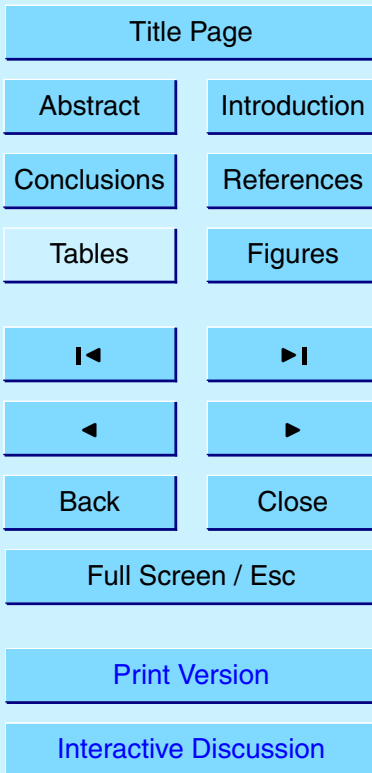

(C) EGU 2004 


\section{Abstract}

Long-term and large-scale correlations between Advanced Very High-Resolution Radiometer (AVHRR) aerosol optical depth and International Satellite Cloud Climatology Project (ISCCP) monthly cloud amount data show significant regional scale relation5 ships between cloud amount and aerosols, consistent with aerosol-cloud interactions. Positive correlations between aerosols and cloud amount are associated with North American and Asian aerosols in the North Atlantic and Pacific storm tracks, and mineral aerosols in the tropical North Atlantic. Negative correlations are seen near biomass burning regions of North Africa and Indonesia, as well as south of the main mineral

aerosol source of North Africa. These results suggest that there are relationships between aerosols and clouds in the observations that can be used by general circulation models to verify the correct forcing mechanisms for both direct and indirect radiative forcing by clouds.

\section{Introduction}

15 Aerosols can perturb atmospheric radiation through a direct effect of scattering and absorption of radiation, and indirect effect via interaction with cloud. Interactions between cloud and aerosols are critical to understanding climate change (IPCC, 1995). Many studies, including measurements and modeling, have been taken to understand the interactions between aerosols and clouds (Warner and Twomey, 1967; Twomey, Radke et al., 1989; Ackerman et al., 2000; Chameides et al., 2002). several mechanisms by which aerosols are thought to interact with clouds: for example by changing the number concentration of cloud droplets which changes both the cloud optical depth and the persistence of clouds in the atmosphere. In addition, aerosols in cloud droplets have different optical properties than pure water cloud droplets, and the aerosols can change the radiative structure of the atmosphere, thereby changing the clouds (IPCC, 2001). In this study, we for the first time explore the effect of aerosols

ACPD

4, 6823-6836, 2004

A global satellite view of aerosol cloud interactions

C. Luo

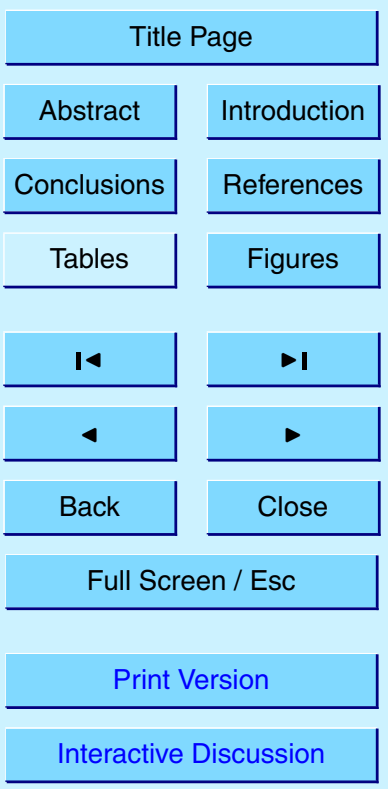

(C) EGU 2004 
on cloud properties using large-scale and long-term correlations between aerosol optical depth from AVHRR and cloud optical depth and cloud amounts from ISCCP. The observed relationships between aerosols and cloud should include the effects of direct and indirect forcing of climate by aerosols.

\section{2. Methodology}

Aerosols optical thickness (AOT) was measured by National Oceanic and Atmospheric Administration (NOAA) Advanced Very High-Resolution Radiometer (AVHRR) polar orbiting satellite. It provides information on aerosol distributions based on backscatter radiation measurements that yield a measure of the "radiatively equivalent" aerosol 10 optical thickness (EAOT) over the oceans. The AOT is estimated from backscatter radiation measurements made at an effective wavelength of $630 \mathrm{~nm}$, and AOT distributions are presented as $1^{\circ} \times 1^{\circ}$ composites of the retrieved data in global area over the oceans (Husar et al., 1997). Validation tests (Ignatov et al., 1995) show good agreement between the AVHRR EAOT measurements (after retuning) and ground based over the ocean averaged from 1984-1999. The plumes in North Atlantic and Arabian Sea are dominated by desert dust (e.g. Tegen et al., 1997). The plume in west coast of South Africa near equator is most likely carbonaceous aerosols emitted by biomass burning (Ducan et al., 2003). The plume in the west North Pacific is likely to be com-

\section{Song and Carmichael, 1999). Due to volcanic eruptions, data is only considered for} bined anthropogenic aerosols and mineral aerosol (Phadnis and Carmichael, 2000; years from 1985-1989, and 1992-1999.

The monthly mean cloud amounts from the International Satellite Cloud Climatology Project (ISCCP) D2 dataset from 1984-1999 (Rossow and Schiffer, 1991, 1999) were used in this study. ISCCP D2 data separate clouds by height of the top of the cloud (low, medium and high clouds), as well as by optical thickness (thin, medium and thick) and whether the clouds are liquid or ice phase. Individual ISCCP observations matched
ACPD

4, 6823-6836, 2004

A global satellite view of aerosol cloud interactions

C. Luo

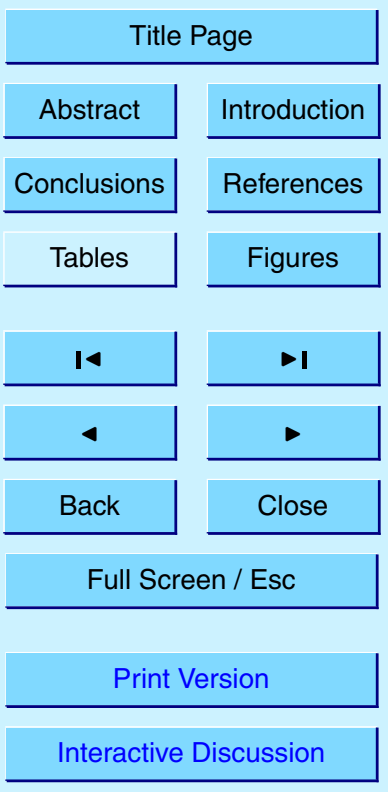

(c) EGU 2004 
with over 670000 individual surface cloud observation, as well as comparisons with the surface based cloud climatology (Rossow and Schiffer, 1999). Comparisons show that total cloud amounts are correct over ocean and lower over the land (Rossow et al., 1993). Comparisons show that the overall bias of ISCCP low-level cloud cover 5 fraction is $<0.1$, and overall cloud types, the rms uncertainty in individuals ISCCP cloud amounts appears to be about 0.15 (Rossow and Schiffer, 1999). Uncertainties in this dataset come from the misidentification of clouds and inaccurate retrieval algorithms and are thought to be $<10 \%$ (Rossow and Schiffer, 1991). Figure 2 shows the total cloud amounts averaged from 1984-1999 of ISCCP data. Observational data suggests 10 that the ISCCP D2 dataset does not clearly identify thin cirrus clouds, especially in the morning hours, perhaps because of low-level clouds beneath the cirrus clouds (e.g. Stubenrauch et al., 1999).

The ISCCP data is interpolated onto the AVHRR 1 degree by 1 degree grid. Because both cloud datasets and aerosols contain large seasonal cycles, we remove the climatological monthly mean and consider only the monthly deviation from mean seasonal cycle (monthly mean-climatological monthly mean) for the correlation analysis. We conduct spatial correlation between time series of aerosols and cloud using monthly averaged anomalies point by point globally. Only correlations that are statistically significant at the $95 \%$ are shown in the resulting figures. We calculate standard deviations for AVHRR AOT and ISCCP cloud amounts. Since the uncertainty of AVHRR AOT is less than 0.04 (Stowe et al., 1997; Cakmur and Miller, 2001), and uncertainty of total cloud amount less than 0.1 (Rossow and Schiffer 1991), our correlation of these anomalies from two data sets is meaningful to the extent that the standard deviation is larger than the uncertainty of each retrieval.

\section{Results}

Figure 3 shows the spatial correlation between total cloud amount (cloud cover) and aerosol optical depth of AVHRR over the ocean globally. It can be seen that the signif-
ACPD

4, 6823-6836, 2004

A global satellite view of aerosol cloud interactions

C. Luo

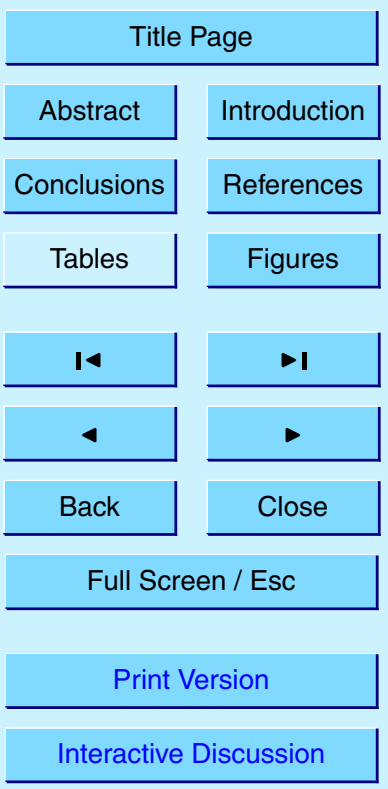

(c) EGU 2004 
icant positive correlations ( 0.2 to 0.5$)$ were found in the North and South Atlantic, and in the North and South Pacific. Significant negative correlations $(-0.2$ to -0.6$)$ were found in the equatorial Atlantic between $10 \mathrm{~W}-30 \mathrm{~W}$, and over Southeast Asia (around Malaysia and Indonesia). There could be several explanations for these correlations: 5 (1), spurious correlation (2), correlated bias in the datasets, (3) both aerosols and clouds driven by same meteorological situation, and (4), interactions between aerosols and clouds. Given the magnitude of correlation coefficient ( $r>0.3)$, and the number of data in each point, the correlations are significant at a confidence level that is $>99.9 \%$, suggesting that spurious correlations are not responsible for the correlations seen in

10 Fig. 3. Noting that aerosol optical depths are generally two order of magnitudes smaller than cloud optical depths (Husar et al., 1997; Rossow and Schiffer, 1993), it seems unlikely that aerosol optical depth could cause significant artifact in the cloud optical depths, although it is likely that the thinnest clouds will be the most susceptible to this artifact. We cannot eliminate that meteorological factors are simultaneously forc15 ing both aerosol and cloud changes, although we reduce the chance of this by using monthly anomalies from all months, and thus the large scale forcing will be seasonally varying. The results are also consistent with an interaction between clouds and aerosols, and next we explore the implications that these represent interactions between clouds and aerosols.

As discussed above, the ISCCP data segregates the data into high, medium and low level clouds. Analysis of the different types of clouds shows that the positive correlations seen in the North Pacific, North Atlantic, South Pacific and South Atlantic tend to be seen the strongest in the low level clouds, while the negative correlations tend to be seen in the high level clouds, with a positive anomaly in the low level clouds in 25 the same locations. The positive correlation off the coast of North Africa and the negative anomaly in the equatorial Atlantic region were seen in correlation just with mineral aerosol (Mahowald and Kiehl, 2003), and are likely to be due to mineral aerosols. The positive correlations of anomalies in the northern hemisphere storm tracks in the North Atlantic and North Pacific are seen in both low and medium level clouds.
ACPD

4, 6823-6836, 2004

A global satellite view of aerosol cloud interactions

C. Luo

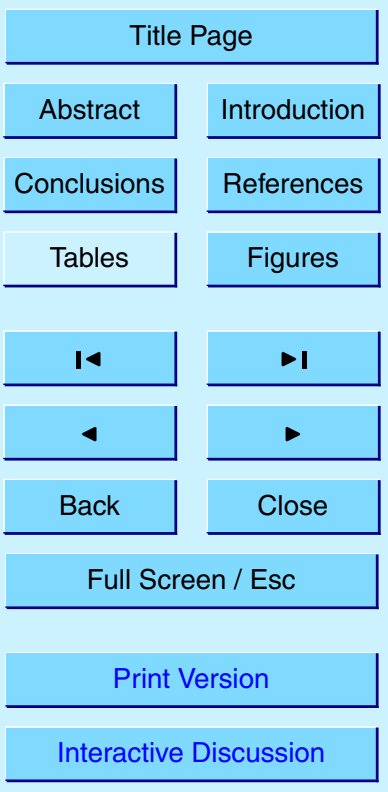

(c) EGU 2004 
Also seen in Fig. 3 is evidence for interactions between biomass burning aerosols and clouds in the South Atlantic, equatorial Atlantic and near Indonesia and Malaysia. Studies have suggested that biomass burning aerosols can interact with clouds both through changes in the cloud microphysics as well as vertical structure changes (Ack5 erman et al., 2000; Levine, 1991; Levine et al., 1995). Since biomass burning tends to occur during distinct seasons we look for correlations during those seasons to isolate the impact of biomass burning. Figure 4 shows the correlations between biomass burning season (a: July-November) and non-biomass burning (b: January-June and December) in Indonesian/Malaysian region; biomass burning season (c: January-March, 10 and December) and non-biomass burning season (d: April-May, October-November) in North Africa; and biomass burning season (e: June-October) and non-biomass burning season (f: January-May, November-December) in South America and South Africa. For the first two cases, the negative anomalies close to the biomass burning areas are stronger during the biomass burning season. However, for the case of the 15 South Atlantic, the signals are less clear during the biomass burning season. This may be due to interference in the equatorial region with the equatorial biomass burning (seen in Figs. 4c and d), or due to other causes. There is a hint of higher negative anomalies close to the coast of Brazil and between Madagascar and Africa during the biomass burning season. These results suggest that in parts of the globe there is a decrease in cloud amount (especially high cloud) during anomalously high biomass burning aerosol months.

There are positive anomalies in the eastern South Pacific (Fig. 3) that appear to be associated with very low levels of sea salt or sulfate aerosol optical depths (Fig. 1) and thus may well be spurious. This may account for the lack of a clear signal for biomass burning aerosols in the South Atlantic - this region also has low optical depths seen in the AVHRR retrievals (Fig. 1). The qualitatively similar results were obtained as Fig. 3 using the NOAA Total Ozone Monitoring Spectrometer (TOMS) Absorbing Aerosol Index (AAI) monthly averages for 1984-1990 (the most stable period of the TOMS AAI, Torres et al., 1998; personal communication, O. Torres, 2000) instead of
ACPD

4, 6823-6836, 2004

A global satellite view of aerosol cloud interactions

C. Luo

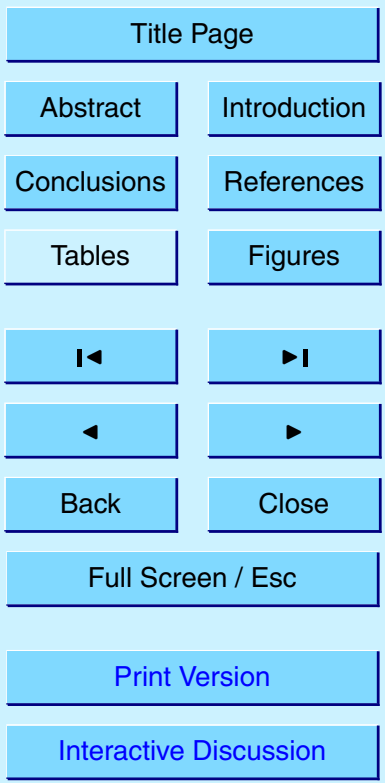

(C) EGU 2004 
AVHRR, except that the storm tracks do not show up as well (consistent with sulfate and organic carbon aerosols not being absorbing aerosols detected by the TOMS AAI) and the signals are less distinct (consistent with the shorter time series).

\section{Summary}

5 This is first time that long-term and large-scale spatial correlation between satellite retrieved aerosol optical depth and satellite-derived cloud amount have been presented. The significant high correlations between anomalous monthly mean aerosol optical depth from AVHRR (Husar et al., 1997; Ignatov et al., 1995) and monthly anomalies in cloud amounts from ISCCP (Rossow and Schiffer, 1991, 1993, 1999) were found 10 in high mineral aerosol, biomass burning aerosol and anthropogenic aerosols areas, such as North Atlantic, North Pacific and Indonesia/Malaysian regions. Because we conducted a correlation analysis, we cannot eliminate spurious correlations although they are unlikely at the statistical significance levels we show here. Our results could also be due to correlative biases in the satellite retrieved datasets, although since we

use different datasets, this is reduced in likelihood. Finally our results can be due to meteorology driving both aerosol optical depth and cloud amount fluctuations, aerosol direct radiative forcing impacting clouds, or aerosols interacting with the microphysics in clouds. Other studies have shown that aerosol cloud interactions can be important (e.g. Albrecht, 1989; Charlson et al., 1992; Schwartz, 1996). The results here are consistent with anthropogenic industrial aerosols in the North Allantic and North $\mathrm{Pa}$ cific, mineral aerosols in the North Atlantic and biomass burning aerosols in equatorial Africa and Indonesia/Malaysia interacting with clouds.

As long as our results are not due to correlated biases in the datasets or spurious correlations, these observations offer a method for testing aerosol models and their feedbacks on climate in general circulation models. The results shown here can be due to meteorology driving both aerosols and clouds, aerosol radiative impacts on circulation (and thus clouds) and aerosol microphysics interacting with clouds - all processes
ACPD

4, 6823-6836, 2004

A global satellite view of aerosol cloud interactions

C. Luo

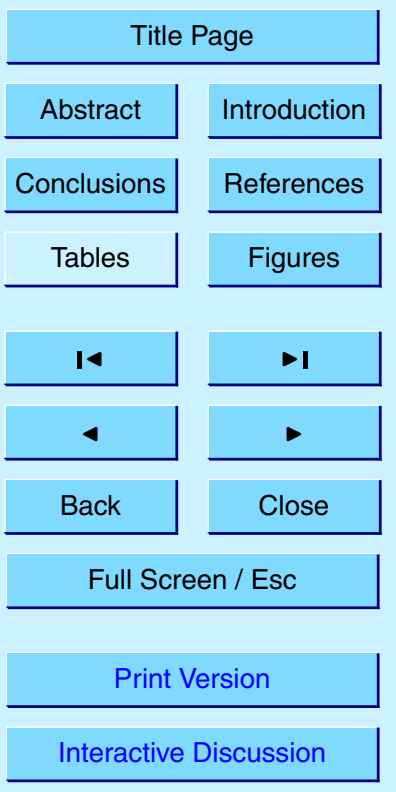

(c) EGU 2004 
that are included in general circulation models today. Aerosol-cloud interactions are one of the important feedbacks we need to constrain for understanding human impacts on climate (IPCC, 2001), and this study provides a method for constraining aerosol forcing on climate in general circulation models.

5 Acknowledgements. This work was supported by NASA-IDS (NAG5-9671 (NM), NASA-NIP (NAG5-8680 (NM) and NSF-Biocomplexity (OCE-9981398 (NM)).

\section{References}

Ackerman, A. S., Toon, O. B., Stevens, D. E., Heymsfiels, A. J., Ramamathan, V., and Welton, E. J.: Reduction of tropical cloudness by soot, Science, 288, 1042-1047, 2000.

10 Albrecht, B. A.: Aerosols, cloud microphysics and fractional cloudness, Sci. Rep., 245, 1227$1230,1989$.

Arino, O. and Melinotte, J.-M.: Fire index atlas, Earth Obs. Q., 50, 11-16, 1995.

Cakmur, R. V. and Miller, R. L.: A comparison of seasonal and interannual variability of soil dust aerosols over the Atlantic Ocean as inferred by the TOMS AI and AVHRR AOT retrievals, J. Geophys. Res., 106, 18287-18303, 2001.

Chameides, W. L., Luo, C., Saylor, R., Streets, D., Huang, Y., and Bergin, M.: Correlation between model-calculated anthropogenic aerosols and satellite-derived cloud optical depths: Indication of indirect effect? J. Geophys. Res., 107, doi:10.1029/2000JD000208, 2002.

Charlson, R. J., Schartz, S. E., Hales, J. M., Cess, R. D., Coakley Jr., J. A., Hansen, J. E., and Hofmann, D. J.: Climate forcing by anthropogenic aerosols, Science, 255, 423-430, 1992.

Duncan, B. N., Martin, R. V., Staudt, A. C., Yevich, R., and Logan, J. A.: Interannual and Seasonal Variability of Biomass Burning Emissions Constrained by Satellite Observation, J. Geophys. Res., 108, doi:10.1029/2002JD002378, 2003.

Husar, R. B., Prospero, J. M., and Stowe, L. L.: Characterization of tropospheric aerosols over the ocean with NOAA advanced very high resolution radiometer optical thickness operational product, J. Geophys. Res., 102, 16 889-16909, 1997.

Ignatov, A., Stowe, L., Sakerin, S., and Korotaev, G.: Validation of the NOAA/NESDIS satellite aerosol product over the North Atlantic in 1989, J. Geophys. Res., 100, D3, 5123-5132, 1995.

ACPD

4, 6823-6836, 2004

A global satellite view of aerosol cloud interactions

C. Luo

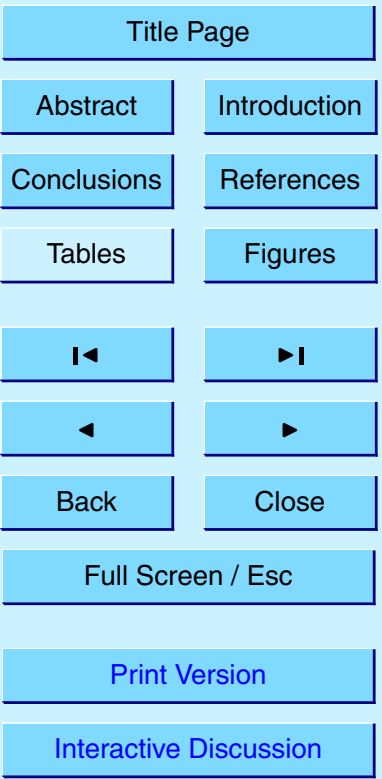

(C) EGU 2004 
Intergovernmental Panel on Climate Change (IPCC), Climate Change 1994: Radiative Forcing of Climate Change and an Evaluation of the IPCC IS92 Emission Scenario, edited by: Houghton, J. T., et al., Cambridge Univ. Press, New York, 339 pp., 1995.

Intergovernmental Panel on Climate Change (IPCC), Climate Change 2001: edited by:

5 Houghton, J., Ding, Y., Griggs, D. J., Noguer, M., van der Linden, P. J., Dai, X., Maskell, K., and Johnson, C. A., 881 pp., Cambridge Univ. Press, New York, 2001.

Global Biomass Burning: Atmospheric, Climatic, and Biospheric Implications, edited by: Levine, J. S., The MIT Press, Inc., 1991.

Levine, J. S., Cofer, W. R., Cahoon, D. R., and Winstead, E. L.: Biomass Burning: A Driver for Global Change, Environ. Sci. Tech., 29, 120A-125A, 1995.

Mahowald, N. and Kiehl, L.: Mineral aerosol and cloud interactions, Geophys. Res. Lett., 30, doi:10.1029/2002GL016762, 2003.

Phadnis, M. J. and Carmichael, G. R.: Forest Fire in the Boreal Region of China and its Impact on the Photochemical Oxidant cycle of East Asia, Atmos. Environ., 34, 483-498, 1999.

15 Radke, L. F., Coakely Jr., J. A., and King, M. D.: Direct and remote sensing observations of the effects of ship on clouds, Science, 246, 1146-1148, 1989.

Rossow, W. B. and Schiffer, R. A.: ISCCP cloud data products, Bull. Amer. Meteor. Soc., 72, 2-20, 1991.

Rossow, W. B. and Garder, L. C.: Validation of ISCCP cloud detections, J. Climate, 6, 23702393, 1993b.

Rossow, W. B. and Schiffer, R. A.: Advances in Understanding Cloud from ISCCP, Bull. Amer. Meteor. Soc., 80, 2261-2287,1999.

Schartze, S.: The Whitehouse Effect-shortwave radiative forcing of climate by anthropogenic aerosols: An overview, J. Aerosol Sci., 27, 35-382, 1996.

Song, C. H. and Carmichael, G.: The Aging Processes of Naturally Emitted Aerosol During Long Range Transport, Atmos. Environ., 33, 2203-2218, 1999.

Stowe, L., Ignatov, A., and Singh, R.: Development, Vilidation, and Potential enhancements to the second generation operational aerosol product at the National Environmental Satellite, Data and Information Service of the National Oceanic and Atmospheric Administration, J.

Stubenrauch, C. J., Rossow, W. B., Cheruy, F., Chedin, A., and Scott, N. A.: Clouds as seen by satellite sounders (3I) and images (ISCCP), Part I: Evaluation of cloud parameters, J. Clim., 12(8), 2189-2213, 1999.

ACPD

4, 6823-6836, 2004

A global satellite view

of aerosol cloud interactions

C. Luo

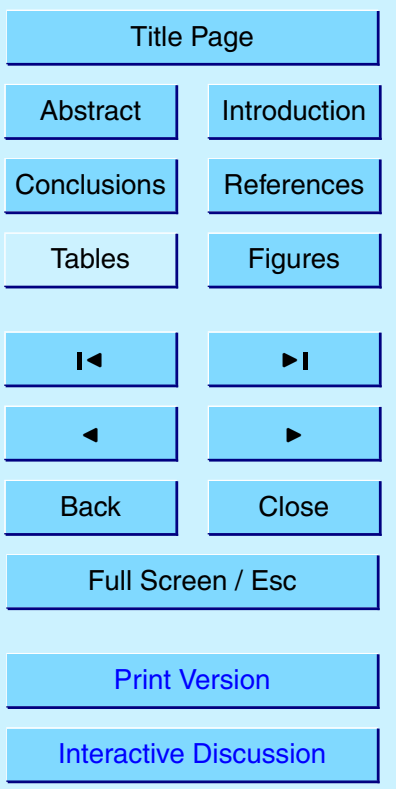

(C) EGU 2004 
Tegen, I., Hollrig, P., Chin, M., Fung, I., Jacob, D., and Penner, J.: Contribution of different aerosol species to the global aerosol extinction optical thickness: Estimates from model results, J. Geophys. Res., 102, 23 895-23 915,1997.

Torres, O., Bhartia, P. K., Herman, J. R., Ahmad, Z., and Gleason, J.: Derivation of aerosol properties from satellite measurements of backscattered ultraviolet radiation: Theoretical basis, J. Geophys. Res., 103, 17 099-17110, 1998.

Twomey, W.: Pollution and the planetary albedo, Atmos. Environ., 8, 1251-1256, 1974.

Waner, J. and Twomey, S.: The production of cloud nuclei by cane fires and the effects on cloud droplet concentration, J. Atmos. Sci., 24, 704-706, 1967.

ACPD

4, 6823-6836, 2004

A global satellite view

of aerosol cloud interactions

C. Luo

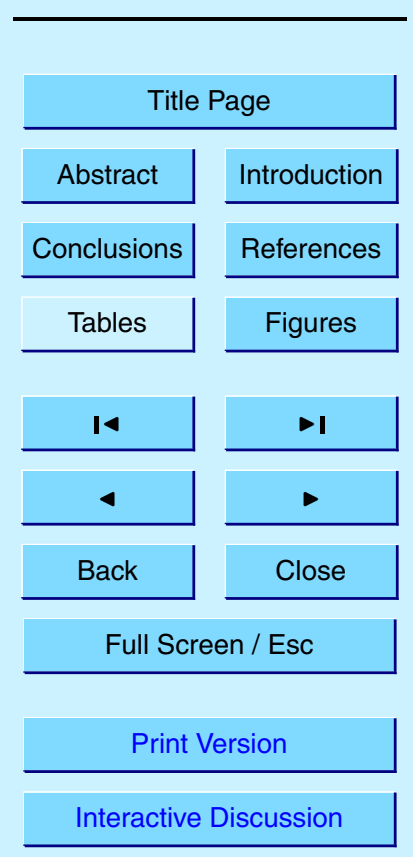

(C) EGU 2004 


\section{ACPD}

4, 6823-6836, 2004

\section{AOT (AVHRR) @ 630 nm}
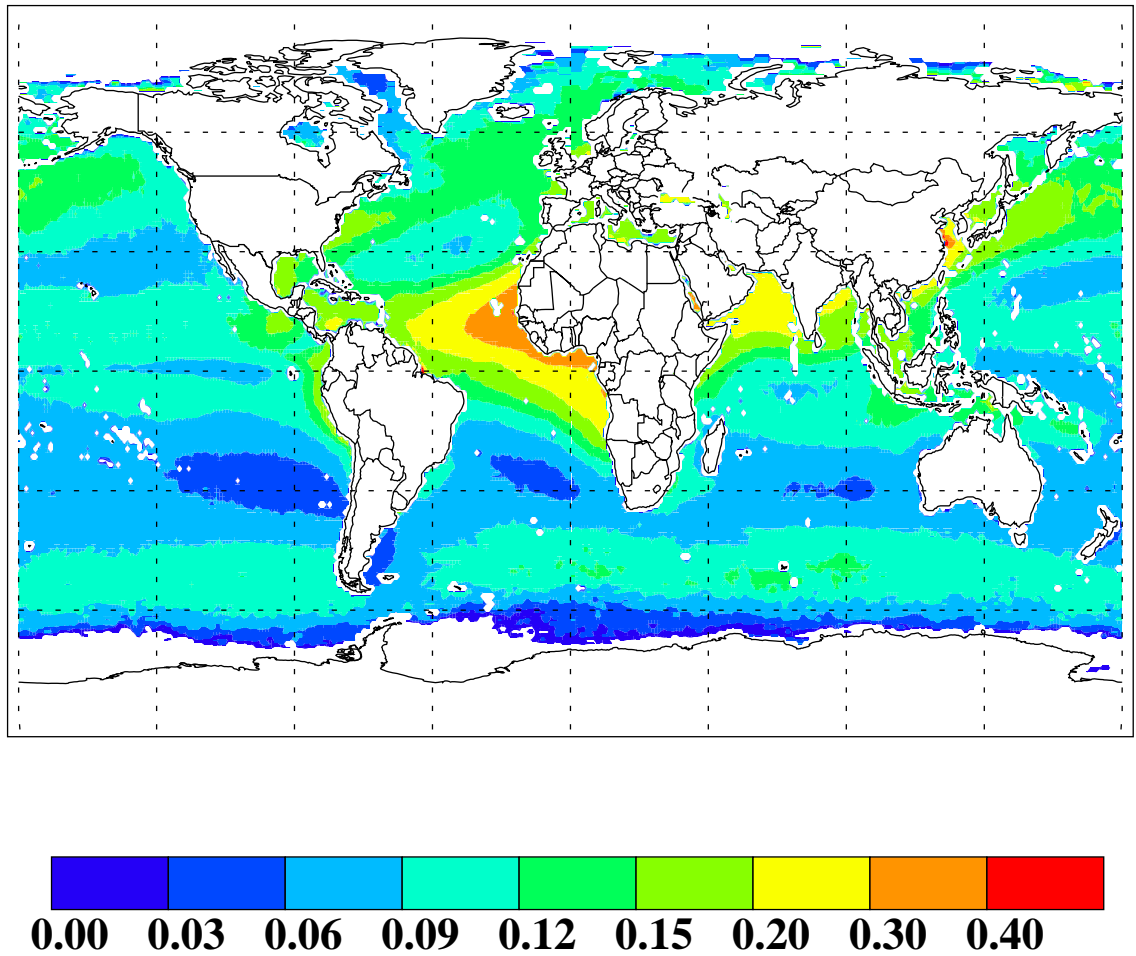

Fig. 1. AVHRR aerosol optical depth at $630 \mathrm{~nm}$ averaged from 1984-1999.
A global satellite view of aerosol cloud interactions

C. Luo

Title Page

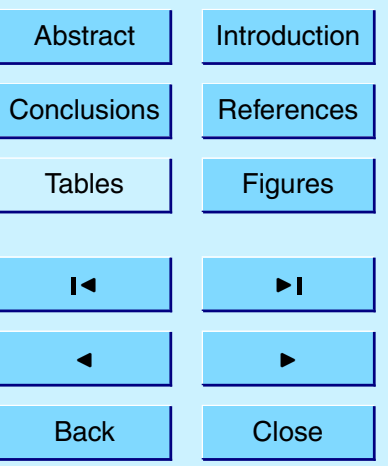

Full Screen / Esc

Print Version

Interactive Discussion

(C) EGU 2004 


\section{ACPD}

\section{Cloud cover average from 84-99 (mon CA)}
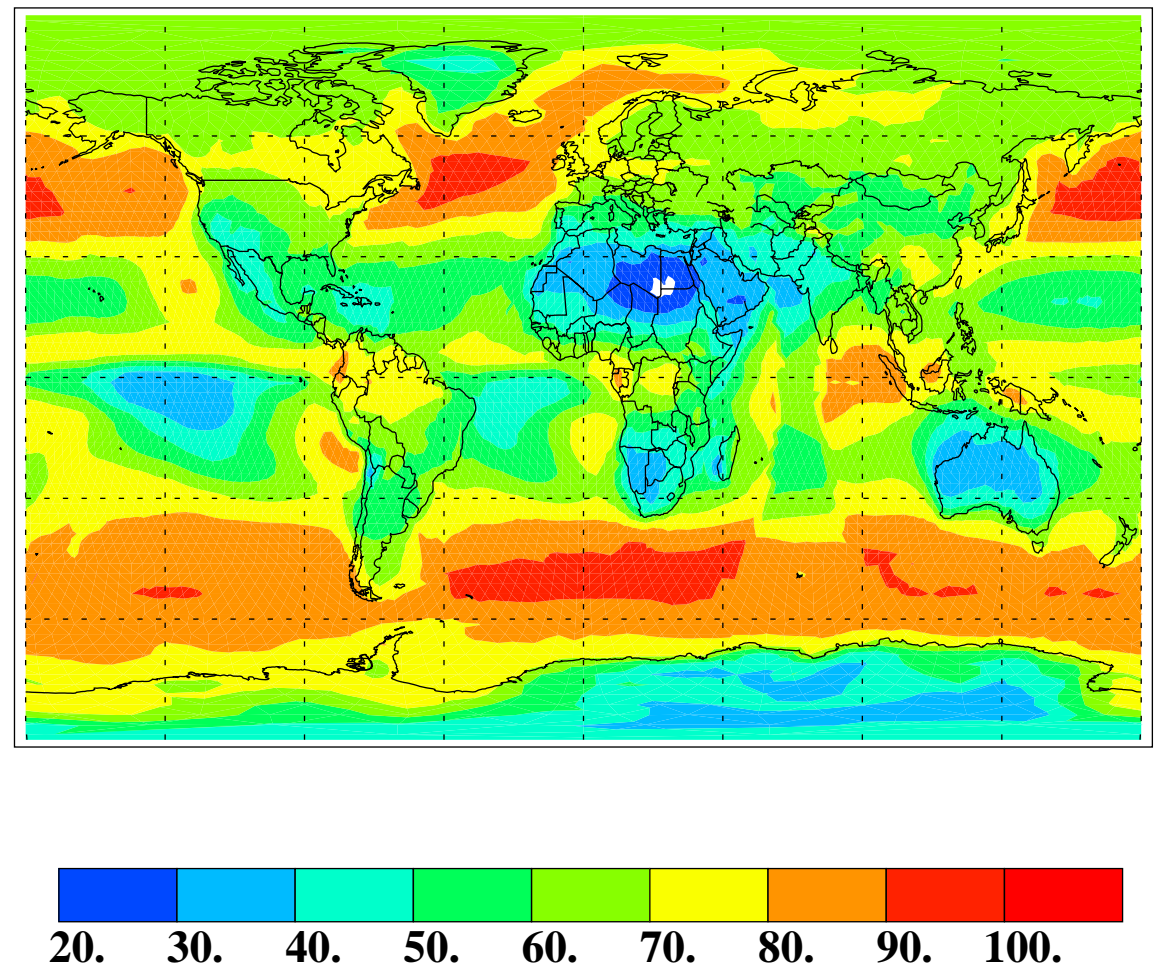

4, 6823-6836, 2004

A global satellite view of aerosol cloud interactions

C. Luo

Title Page

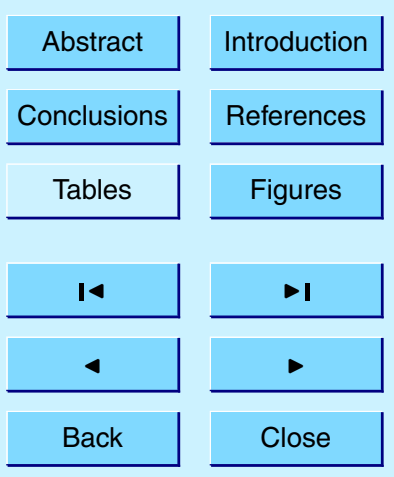

Full Screen / Esc

Print Version

Interactive Discussion

(C) EGU 2004 


\section{ACPD}

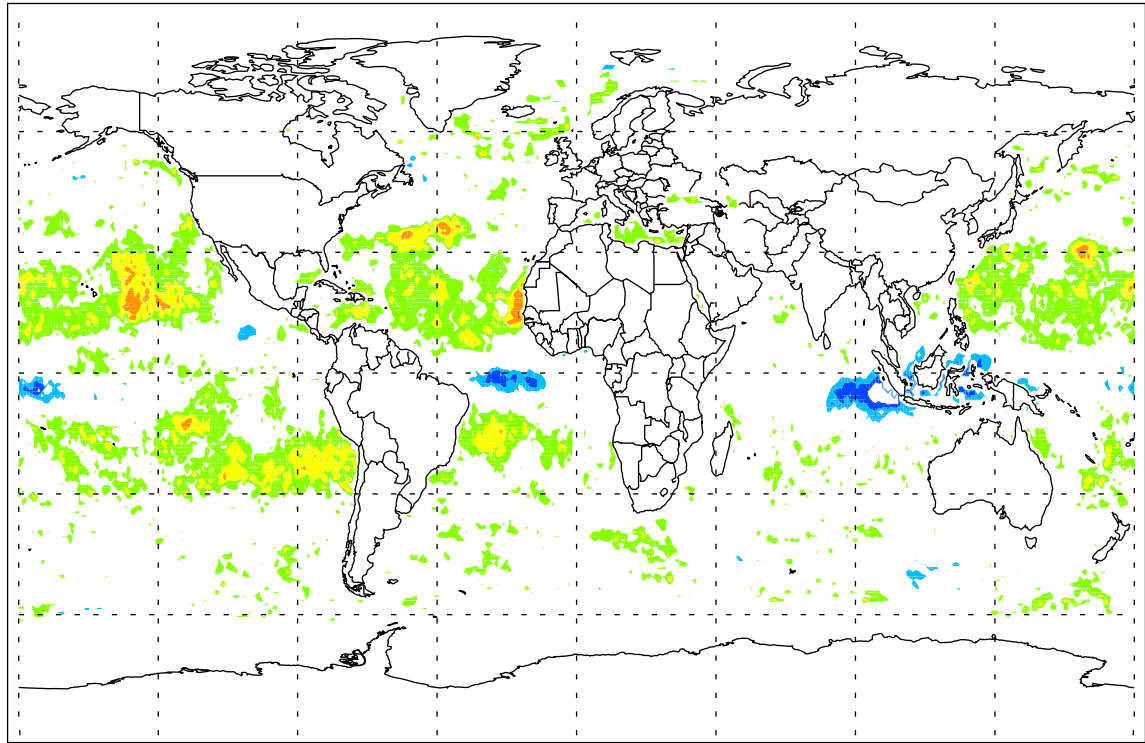

4, 6823-6836, 2004

A global satellite view

of aerosol cloud interactions

C. Luo

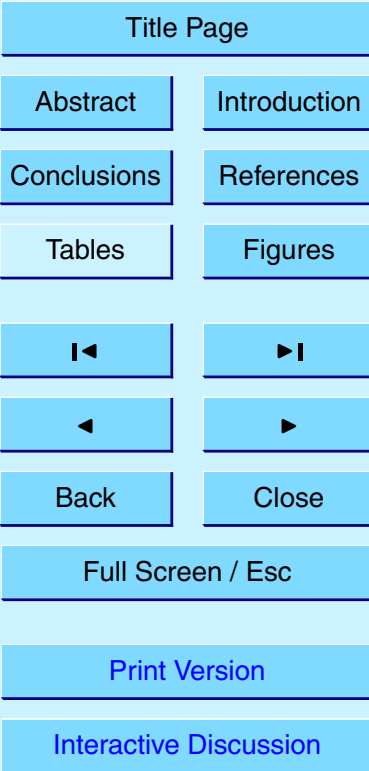

Fig. 3. Spatial correlation between anomalies monthly mean AVHRR aerosol optical depth and anomalies monthly mean ISCCP total cloud amounts, the correlations are significant at the $95 \%$ level at \pm 0.2 , and $>99.9 \%$ level at \pm .30 .

(C) EGU 2004 

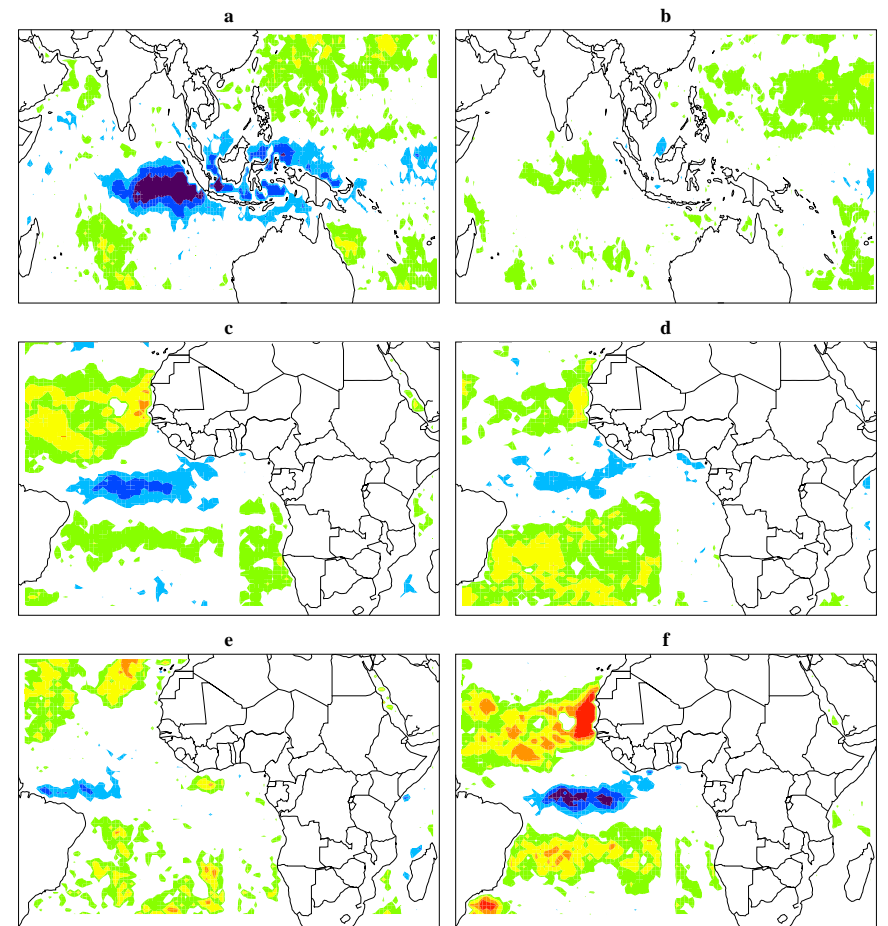

\begin{tabular}{ccc|c|c|c|c|c|c|}
\hline & -0.50 & -0.40 & -0.30 & -0.20 & 0.20 & 0.30 & 0.40 & 0.50
\end{tabular}

Fig. 4. Spatial correlation between anomalies monthly mean AVHRR AOT and anomalies monthly mean ISCCP total cloud amounts in biomass burning and non-biomass burning seasons in (a)-(b): Malaysia \& Indonesia; (c)-(d): North Africa; (e)-(f): South America and South Africa regions, the correlations are significant at the $95 \%$ level at \pm 0.2 , and $>99.9 \%$ level at \pm .30 .

\section{ACPD}

4, 6823-6836, 2004

A global satellite view of aerosol cloud interactions

C. Luo

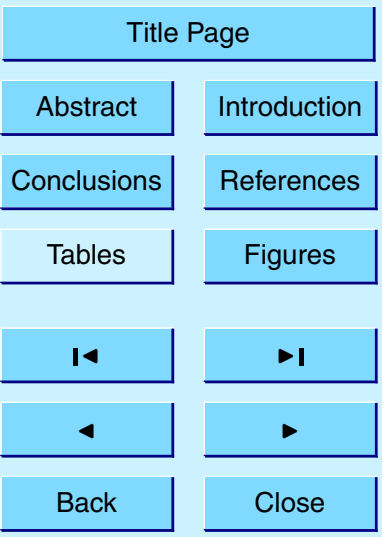

Full Screen / Esc

Print Version

Interactive Discussion

(C) EGU 2004 